\title{
Histological changes within ovarian cortex, oviductal and uterine mucosa in case of ovarian cysts presence in sows
}

\author{
Katarzyna Szulańczyk
}

Department and Clinic of Reproduction, Faculty of Veterinary Medicine, University of Environmental and Life Science, Wrocław, Poland

\begin{abstract}
The aim of study was histological evaluation of oviduct and uterus mucosa in case of cystical ovarian degeneration in sows. Materials for evaluations were received after slaughtering of 294 sows at age of 2-5 years. Sows were eliminated breeding and culled due to reproduction disorders: anoestrus after weaning of piglets, return of estrus, small litters and due to age, number of birth, bad condition after lactation. 20 sows $(6.8 \%)$ had cysts on ovaries. Histological investigations were conducted on reproductive organs of sows with ovarian cysts. Sows were divided onto two groups: 1 . with polycystic ovaries (12 sows), 2. with simple cyst ( 8 sows) occured unilaterally (3 sows) or bilaterally (5 sows). In our studies we noted different kids of ovarian cysts and structural changes in ovarian cortex like decreasing numbers of ovarian folliculi of all generations, increasing of follicular atresia. We compared the state of oviduct and uterus mucosa in case of polycystic ovaries with the histological changes in these tissues when single cysts were present on the ovaries. The single follicular cysts aren't accompanied with important changes in reproductive system. In case of polycystic ovaries the presence of cyst is connected with occurrence of morphological changes in endothelium of oviduct and uterus which would have been a reason of persistent infertility of pigs.
\end{abstract}

Key words: Ovarian cysts, sow, oviduct, uterus

\section{Introduction}

Fertility disturbances lead to culling of female pigs, which result in reduced production. Reproductive failure occurs in many different forms and they are one of the dominating problems in the farms and the reason for the culling of sows. Reproductive function of female pigs is difficult to examine clinically in field conditions therefore slaughterhouse material is a potential source of information concerning porcine fertility problems [4]. Reproductive organs and their physiology of the sow depend upon complex sequence of events both of endocrinological and neuroendocrinological nature, disturbances of which may lead to infertility [6]. The ovarian cysts, as a reason for infertility, is still big and serious problem in breed-

Correspondence: Department and Clinic of Reproduction, Faculty of Veterinary Medicine, University of Environmental and Life Science, Pl. Grunwaldzki 49, 50-366 Wrocław, Poland; tel.:(+4871) 3205302, fax.: (+4871) 3201006,

e-mail:kakulek@wp.pl ing of pigs [11]. There are usually no pathognomonic signs of cystic ovaries in sows except for an irregular or prolonged estrus cycle, permanent anoestrus and infertility. Generally, ovarian cysts in swine offer no clinical problems for pig farms except for a decrease in sow fertility [2]. By assessing the incidence of ovarian cysts in culled animals, it was observed that ovarian cysts are present in approximately $10 \%$ of sows that were culled for fertility problems [1].

Because cystic ovarian disease is an endocrine disorder, the hormonal milieu could create a favorable environment for the development of changes in proliferation and secretory activity of cells of oviduct and uterine membrane mucosa. The endocrinological status of cystic ovarian disease affects these organs functions [11].

The purposes of the present study were to investigate the changes in oviduct and uterus in case of cystic ovarian degeneration and to evaluate whether there are any relationships between presence of different types of ovarian cysts and the change in tunica mucosa of oviduct and uterus. 


\section{Materials and methods}

Animals Reproductive organs from 294, 2-5 years old multiparous sows were collected in a slaughterhouse. The sows were culled due to reproduction disorders: anoestrus after weaning of piglets, return of estrus, small litters and due to age, number of birth, bad condition after lactation. The histological examination has been conducted on organs of 20 (6.8\% of 294 sows) sows, in which we noted presence of cysts on the ovaries, divided into two subgroups: 1.12 sows with polycystic ovaries (more than 5 cysts on one ovary), 2. 8 sows with simple cyst (5 or less cysts on one ovary) occurred unilaterally ( 3 sows) or bilaterally (5 sows).

Histology Evaluations of the ovaries were conducted according to the Kuryszko technique [7]. Sections of ovaries, central part of ampulla and isthmus of oviducts and horn of uterus were fixed in $4 \%$ formalin for $48 \mathrm{~h}$ and processed routinely with paraffin embedding, after which they were cut at $7 \mu \mathrm{m}$ and stained with hematoxylin/eosin.

\section{Results}

In the present study we investigated the histological changes within ovarian cortex, oviductal and uterine mucosa in case of ovarian cycts presence in sows. On the basis of macroscopical examination of reproductive organs from 294 sows we noted the presence of ovarian cysts in 20 sows $(6.8 \%)$. Ovarian cysts occur on one or both ovaries. Bilateral cysts were seen more often $(85 \%)$ than unilateral $(15 \%)$. In histological examination we demonstrate that usually there are different kinds of cysts, one kind is very seldom. We distinguished follicular cysts (Fig. 1), follicular thecalutein cysts (Fig. 2), follicular lutein cysts and cysts of corpus luteum (Fig. 3). The last-mentioned occur seldom (what is consistent with Kuryszko observations on cow's ovarian cysts). The cysts of corpus luteum mostly rise on the base of haematoma of corpus luteum in way of gradually blood resorption. Then the cavity of enlarged corpus luteum fills of the serous fluid. In vesicular cysts membrana granulosa is visibly thinner than in mature folliculi. The thecaluteal follicular cysts are the structures with wide tunica interna which cells undergo luteinization. In follicular luteal cysts all the wall of folliculi undergo luteinization (Fig. 3).

The presence of polycystic ovaries with different types of cysts is accompanied by the morphological changes in endothelium of oviductal and uterine mucosa (Figs. 5,7-9). The obtained results revealed that there is essential relation between the presence of ovarian cysts and increase of number of secretory cells both in ampulla and isthmus of oviduct. The histological changes were seen in uterine mucosa to. We observed an increase of number of secretorycells in superficial epithelium of uterine mucosa and proliferation of secretory segments of uterine glands.

The single follicular cysts aren't accompanied by important changes in reproductive system (Fig. 4,6).
We noted the presence of corpora lutea and ovarian folliculi within ovaries with simple cysts.

We observed that the presence of cysts cause structural changes in ovarian cortex like decreasing numbers of ovarian folliculi of all generations, increasing of follicular atresia especially in increasing and mature folliculi. These morphological changes within ovaries were noted, similarly to changes in oviduct and uterus, especially in case of polycystic ovaries (according to Kuryszko).

\section{Discussion}

In case of polycystic ovaries theca-lutein and lutein cysts have real endocrinological effect on reproductive system because their presence is connected with occurrence of morphological changes in endothelium of oviduct, uterus mucosa (Figs. 5,7-9) which would have been a reason of persistent infertility of culled pigs. The single follicular cysts aren't accompanied with important changes in reproductive system (Figs. 4,6) so we can suspect that they are endocrinologically little active. We observed the presence of corpora lutea and ovarian folliculi within ovaries with simple cysts. This observation confirm possibility of ovulation and pregnancy in sows with simple ovarian cysts.

Fertilization and first stage of embryogenesis take place in oviduct. In ampulla of oviduct, the place of fertilization, ciliated cells dominate. Cilia of these cells move ovum and conceptus in oviduct. The first stages of embryogenesis take place in isthmus. The decisive condition for these processes is proper state of mucosa. Developing conceptus need proper environment which create secretory cells producing oviductal fluid. Both abnormality in transport of gametes (egg cells, sperms) and in production of oviductal fluid may lead to infertility [7]. The tunica mucosa of oviduct is lined by simple columnar epithelium which consist of ciliated and devoid of cilia cells. In epithelium of oviductal mucosa especially important is relation between number of ciliated and secretory cells.

We noted that the presence of ovarian cysts is accompanied by unfavorable changes in oviductal mucosa consisting in increase of secretory cells with simultaneous decrease of ciliated cells and this state fundamentally influence oviduct function. The changes in proportion of cells occur both in ampulla and isthmus. Secretions cover oviductal epithelium. This state promote sticking, accretion of tubal folds and occlusion of oviduct. These alterations may create some problems in migration of gametes and in this way inability to fertilization.

In our studies we showed that there are some morphological changes in epithelium of uterine mucosa in case of polycystical ovaries in sows. In epithelium of uterine mucosa of sows with ovarian cysts the signifi- 

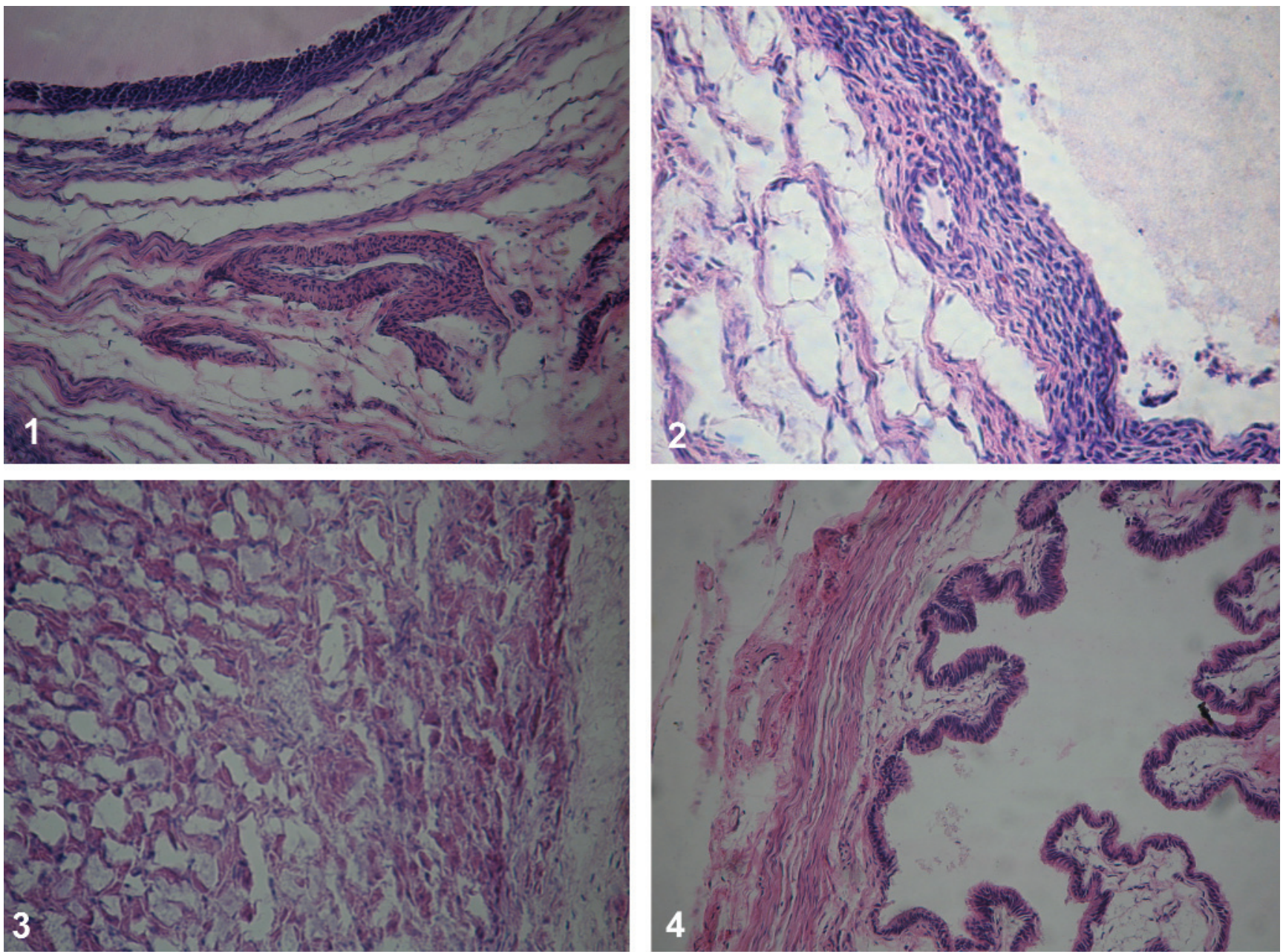

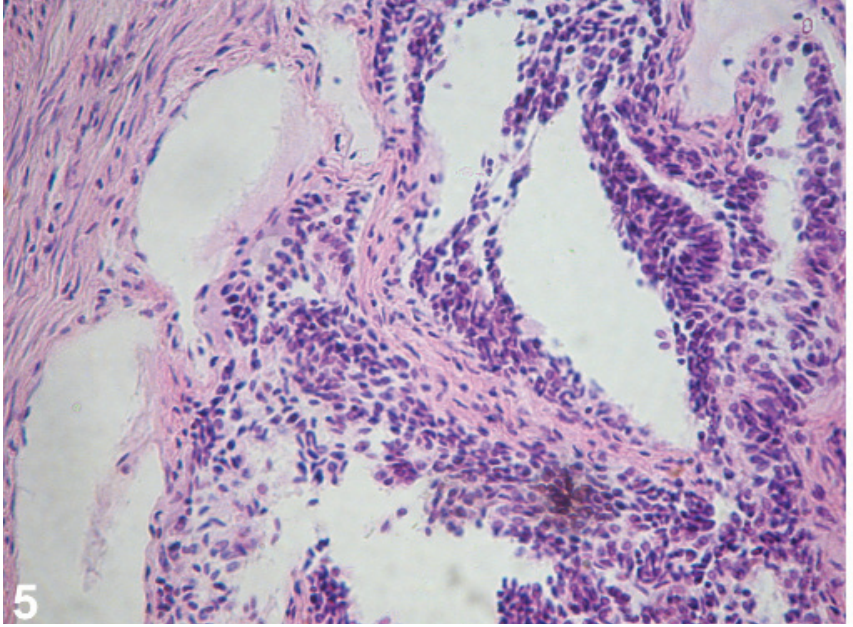

cant changes in proportion of cells and numerous of secretory segments were noted. The main changes in the uterus were seen in the mucosal epithelium and terminal portion of the uterine glands. Secretory segments were cystic dilated with remaining secretions. In our studies we observed increasing proliferation both
Fig. 1. Wall of follicular cyst $(H+E$, magnification $\times 200)$. Fig. 2 . Wall of theca- lutein follicular cyst $(\mathrm{H}+\mathrm{E}$, magnification $\times 400)$. Fig. 3. Thickened, luteinized wall and internal zone of corpus luteum cyst $(\mathrm{H}+\mathrm{E}$, magnification $\times 200)$. Fig. 4. Correct state of oviductal wall in case of single follicular cyst presence $(\mathrm{H}+\mathrm{E}$, magnification $\times 200$ ). Fig. 5. Epithelial cells proliferation of oviductal mucosa in case of follicular theca-lutein, follicular lutein and corpus luteum cysts presence $(\mathrm{H}+\mathrm{E}$, magnification $\times 400)$.

of glandular epithelium and surface epithelium (Figs. 7-9). Hypersecretion of superficial epithelium were noted. The secretion cover the epithelial surface prevent to outflow of fluid from uterine glands [10].

During the estrous cycle, the porcine uterus and especially its endometrium undergoes proliferation 

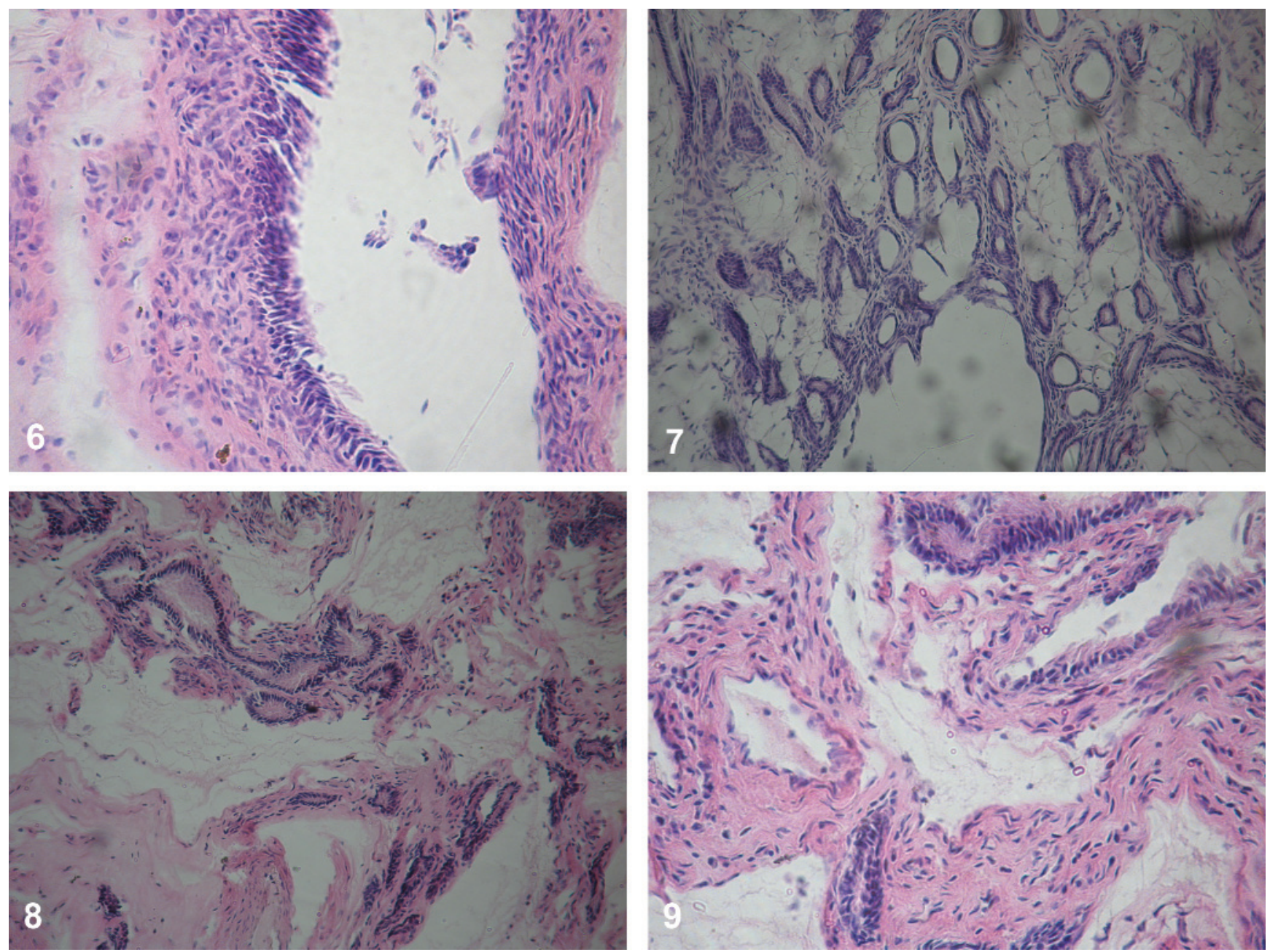

Fig. 6. Correct state of uterine mucosa in case of single follicular cyst presence $(H+E$, magnification $\times 400)$. Fig. 7. Epithelial proliferation of uterine mucosa in case of follicular theca-lutein, follicular lutein cysts presence $(\mathrm{H}+\mathrm{E}$, magnification $\times 200)$. Fig. 8. Glandular proliferation zone in case of follicular theca-lutein, follicular lutein cysts presence $(\mathrm{H}+\mathrm{E}$, magnification $\times 200)$. Fig. 9. Uterine mucosa in case of follicular lutein and corpus luteum cysts presence, glandular proliferation of endometrium $(\mathrm{H}+\mathrm{E}$, magnification $\times 400)$.

and differentiation in response to changes in sex steroid hormone levels [4]. The mammalian uterus is a truly remarkable organ whose physiological and morphological characteristics change not only within but also between reproductive states. The majority of these changes in uterine structure and function are attributable to ovarian hormones [5]. Surface and glandular epithelia are considered to be functionally different cell populations regarding morphology and secretory activities. Endometrial glands synthesize, transport and secrete substances that are essential for conceptus survival and development in pigs. Proliferative activities showed significant differences between stages of estrous cycle only in the glandular epithelium. The high proliferative rate of uterine glands can be explained as a preparation for secretory activity and growth during pregnancy establishment. The endometrium shall create an appropriate environment for the growing embryos [9]. One reason for very early embryonic death is non-parallel development of conceptuses and endometrium [5].

The proliferative and secretory changes are primarily controlled by ovarian steroid hormones. The endometrial epithelium cells respond to hormones and in this way play a significant role in endometrial physiology and pathology to [8]. The endocrinological abnormalities in cystic ovarian disease may have complex effects on the endometrium which is a steroid hormone-dependent tissue whose cellular components and tissue growth and remodeling respond to changes in circulating hormones [3].

In conclusion, the obtained results showed essential relation between the presence of ovarian cysts and histological changes in ovaries, oviductal and uterine mucosa which cause reproductive organ dysfunctions. If this state lasts long time may lead to permanent changes in mentioned organs and, in consequently, cause persistent infertility of pigs and culling of the females. 


\section{References}

[1] Heinonem M, Leppavuori A, Pyorala S. Evaluation of reproductive failure of female pigs based on slaughterhouse material and herd record survey. Anim Reprod Sci. 1998;52:235244.

[2] Karveliene B, Zilinskas H Riskevicience V. Post-mortem Examination of Sows Genital Organs Culled for Reproductive Disturbances and Immunohistochemical Studies on Ero and PR A Receptors in the Anoestral Sows Uterus. Reprod Dom Anim. 2007;42:275-281.

[ 3] Villavicencio A, Bacallao K, Avellaira C, Gabler F, Fuentes A, Vega M. Androgen and estrogen receprtors and co-regulators levels in endometria from patients with polycystic ovarian syndrome with and without endometrial hyperplasia. Gynecol Oncol. 2006;103:307-314.

[ 4] Fitko R, Kucharski J, Szlezyngier b. The importance of thyroid hormone in experimental ovarian cyst formation in gilts. Anim Reproduct Sci. 1995;39:159-168.

[ 5] Castagna CD, Peixoto CH, Bortolozzo FP, Wentz I, Neto GB, Ruschel F. Ovarian cysts and their consequences on the reproductive performance of swine herds. Anim Reprod Sci. 2004; 81:115-123.

[6] Kuryszko J. Badania nad występowaniem cyst jajnikowych i ich związkiem z czynnością jajnika i stanem błony śluzowej jajowodu i macicy u krów. Zesz. AR Wrocław - Dissertation No.86,1990.

[ 7] Twardoń J, Wojciechowski R, Kuryszko J. Ovarian cysts and epithelium state of oviduct and uterine mucosa in sows. Reprod Dom Anim. 1999;34:41.

[8] Kaeoket K, Persson E, Dalin A-M. The sow endometrium at different stages of the oestrous cycle: studies on morphological changes and infiltration by cells of immune system. Anim Reproduct Sci. 2001;65:95-114.

[9] Sukjumlong S, Kaeoket K, Dalin A-M, Persson E. Immunohistochemical Studies on Oestrogen Receptor Alpha (ER $\alpha)$ and the Proliferative Marker Ki-67 in the Sow Uterus at Oestrus and Early Pregnancy. Reprod Dom Anim. 2004;39: 361-369.

[10] Mylonas I, Jeschke U, Shabani N et al. Immunohistochemical analysis of estrogen raceptor alpha, estrogen receptor beta and progesterone receptor in normal human endometrium. Acta Histochem. 2004;106:245-252.

[11] Giudice LC. Endometrium in PCOS: Implantation and predisposition to endocrine CA. Best Pract Res Clin Endocrinol Metabol. 2006;20:235-244.

Submitted: 15 February, 2008 Accepted after reviews: 25 September, 2008 